\title{
Non-cardiac manifestations of Marfan syndrome
}

\author{
Anne H. Child \\ Molecular and Clinical Sciences Research Institute, St George's University of London, Cranmer Terrace, London, UK \\ Correspondence to: Dr. Anne H. Child, MD, FRCP. Reader in Cardiovascular Genetics, Molecular and Clinical Sciences Research Institute, St \\ George's University of London, Cranmer Terrace, London SW17 0RE, UK. Email: achild@sgul.ac.uk.
}

\begin{abstract}
Because of the widespread distribution of fibrillin 1 in the body, Marfan syndrome (MFS) affects virtually every system. The expression of this single dominantly inherited gene is variable within a family, and between families. There is some genotype-phenotype correlation which is helpful in guiding long-term prognosis, and management. In general gene mutations have been reported in clusters, with those having mainly ocular manifestations occurring in exons 1 to 15 of this 65-exon gene; those causing cardiac problems often involving cysteine replacement in a calcium binding EGF-like sequence; the most severe mutations occurring in exons 25-32, causing neonatal MFS diagnosed at birth, and severe enough to cause death frequently before the age of 2 . Other correlations will certainly be found in future. This condition is progressive, and the manifestations unfold according to age. For example, if the lens is going to dislocate this usually occurs by age 10; scoliosis usually presents itself between the ages of 8 and 15; height should be monitored carefully between the onset of puberty and cessation of growth approximately age 17 or 18 . Holistic care should be offered by one doctor who oversees the patient's welfare. This should be a paediatrician, paediatric cardiologist, or general practitioner in the case of an affected child. Thereafter, the physician in charge of the most seriously affected system should be aware that other systems need to be managed through a referral network.
\end{abstract}

Keywords: Marfan syndrome (MFS); management; non-cardiac; systemic

Submitted Jul 25, 2017. Accepted for publication Oct 02, 2017.

doi: 10.21037 /acs.2017.10.02

View this article at: http://dx.doi.org/10.21037/acs.2017.10.02

\section{Marfan syndrome (MFS) in the emergency setting}

The aim of a holistic management programme is to prevent emergencies arising by treating medically, or surgically, at the optimum time. However, emergencies do occur and should be managed as follows. Chest pain, abdominal pain, shortness of breath, syncope, and neurological complaints may all be presenting symptoms in aortic dissection. Thorough investigation should be undertaken no matter what the hour of day or night is, before the patient is discharged. The patient may need urgent transfer to the regional cardiothoracic centre.

\section{Pneumothorax}

Spontaneous pneumothorax should be excluded in the investigation of an MFS patient with chest pain or unexplained breathlessness by doing an erect posteroanterior (PA) chest $\mathrm{X}$ ray. If it is small and the patient is asymptomatic, this can be managed expectantly. However, if the patient is symptomatic, the pneumothorax should be aspirated. Pneumothorax may recur, and the thoracic surgeon must decide when to offer pleurodesis, and/or surgical removal of bullae in the upper lobe (1). Sudden changes in pressure are not recommended for such a patient, so skydiving and deep-sea diving are contraindicated. Commercial air travel is generally safe after 6 months.

\section{Endocarditis}

MFS patients have an increased risk of endocarditis, even in the absence of a significant valvular lesion, the risk is further increased if the patient has aortic wall or aortic or mitral valve implants. The need to follow up-to-date guidelines for 
antibiotic prophylaxis is important $(2,3)$.

\section{General anesthesia}

General anesthesia carries an increased morbidity and mortality risk in MFS, including difficult intubation, thus during procedures under general anesthetic in the emergency care setting, the need for an experienced anesthetist is emphasised (4).

\section{Visual disturbance}

Emergency presentations of ocular manifestations may include lens dislocation, retinal detachment, or sudden onset glaucoma. If increased intraocular pressure occurs due to dislocated lens, vitreolensectomy is necessary to save the eye. Urgent referral to an ophthalmologist is important. Retinal detachment may present as loss of vision preceded by a curtain effect. In order to achieve good results, early diagnosis and referral for treatment are very important.

\section{Infantile and neonatal Marfan}

Those most severely affected may be diagnosed at birth (neonatal MFS) or within the first year of life (infantile). Early recognition can aid management, and genetic counselling can be provided to the parents.

Gene mutations have been reported in clusters, with those having mainly ocular manifestations occurring in exons 1 to 15 of this 65 -exon gene; those causing cardiac problems often involving cysteine replacement in a calcium binding EGF-like sequence; the most severe mutations occurring in exons 25-32, causing neonatal MFS diagnosed at birth, and severe enough to cause death frequently before the age of $2(5,6)$.

\section{Infantile MFS}

Infants diagnosed in the first three months of life may be recognised by a typical long, thin appearance, with long head and face (dolichocephaly), wise facial appearance with deep-set eyes, large corneas and dislocated lenses, large soft ears, high arched palate, small chin, loose joints, arachnodactyly, contractures of fingers and large joints, flat feet, and anterior chest deformity. Additional features may include downward slanting palpebral fissures, retinal detachment, low set ears, partial cleft palate, dislocated hip, inguinal hernia, overlapping toes, in-turned or out-turned feet, poor muscle tone, and very thin muscles. Infants with severe heart disease have a significant mortality risk of approximately $15 \%$ in the first year of life. Familial cases have a better long-term outlook, generally following the family pattern of involvement. Homocystinuria and Beals syndrome should be ruled out.

Once a new mutation in the $F B N 1$ gene is detected, and parents checked for the same mutation, the majority of parents can be reassured that their child has a spontaneous mutation, as occurs in $25 \%$ of cases of MFS. The population incidence is $1 / 3,300$ (7). If one parent is shown to be carrying the mutation, then all siblings of the proband should be screened for the same mutation. If a familial mutation is discovered, then any subsequent pregnancy could be monitored prenatally, or preimplantation genetic diagnosis could be offered.

\section{Ophthalmic abnormalities}

The ocular manifestations are varied, and include myopia, corneal flattening, ectopia lentis (EL), and retinal detachment. The prevalence reported suggests that $30 \%$ of patients have EL and 15\% have retinal detachment (8).

\section{Ectopia lentis}

The lens subluxation or dislocation is due to weakness of the zonular filaments secondary to abnormal fibrillin-1. Other genes can cause EL in the absence of systemic abnormality, thus careful genetic investigation must be undertaken to achieve a definite diagnosis (9). Subluxation of the lens is usually bilateral and symmetrical. This usually occurs in the first two decades, and is usually stable once an individual reaches their 20s. The subluxed lens can develop a cataract. Anterior subluxation of the lens may interfere with the drainage angle of the eye, resulting in raised intraocular pressure and secondary glaucoma. If visual acuity remains relatively good, optical correction with appropriate glasses or contact lenses should maintain adequate vision. If there is troublesome fluctuation of vision caused by instability of the lens then surgical correction (viteolensectomy) should be considered. Removal of both the lens and the vitreous gel minimizes the chance of subsequent retinal detachment (10). Laser or cryotherapy can be applied to areas of lattice retinal degeneration or retinal tears which might predispose to detachment. Detachment itself can be repaired using intraocular expansile gas or silicone oil tamponade. A lens implant may be sutured into the posterior chamber, or 
placed in the anterior chamber (11).

\section{Myopia}

Myopia is common in MFS patients and can be corrected with glasses or contact lenses.

\section{Other ophthalmic problems}

Strabismus (squint) is common in MFS, and may be associated with amblyopia (12). The cornea of patients is reported to be thinner and flatter than the normal population, and therefore it is not advisable for these patients to undergo corneal refractive surgery (13).

Regular checks of visual acuity and refractive error should be carried out in childhood to detect abnormalities. It is advisable that children refrain from sports with excessive head contact or deceleration such as boxing or bungee jumping. Parents should maintain a degree of awareness for any loss of vision that the child may experience and seek prompt advice.

\section{Skeletal problems in MFS}

\section{Height}

Excessive growth is a diagnostic feature of MFS, with most patients achieving height over the $97^{\text {th }}$ percentile, with average body weight $25^{\text {th }}$ percentile, resulting in a long slim build. If serial annual measurements of a child's height indicate that they are going to be $203 \mathrm{~cm}$ or taller in males, and $188 \mathrm{~cm}$ or taller in females, then they should be referred to growth clinic for consideration of hormone therapy to shorten final height. Empirically, this probably saves the child $1(2.5 \mathrm{~cm})$ on their final predicted height, but further longitudinal studies must be performed to verify that hormonal therapy during the growth spurt is effective.

\section{Scoliosis}

The most common skeletal manifestation is scoliosis, seen to some degree, in at least $60 \%$ of patients (13). The thoracic spine is the most common region affected, followed by the thoracolumbar junction. There is a higher incidence of double or triple major curves (14). If thoracic lordosis occurs, and is coupled with pectus excavatum, this can result in a reduced AP diameter of the chest with compression of large airways, and predisposition to recurrent chest infections. Such patients are also at higher risk during cardiac surgery. The scoliosis in MFS often has rapid progression with poor response to bracing. Moreover, the vertebral shape is affected, which makes operative treatment challenging (13). This includes narrow pedicles, vertebral and sacral scalloping, wide transverse processes, thin laminae and low bone mineral density.

Other aspects of skeletal development are frequently abnormal, including leg length inequality, angular deformities of the lower extremities, pes planus, and flexion contracture at the elbows. Protrusio acetabuli is also common (15).

\section{Cervical spine}

Patients have a loss of normal cervical lordosis or reversal of lordosis with cervical kyphosis in approximately $16 \%$ of cases (16). Also, particularly in children, there is an increased atlantoaxial movement on flexion-extension, and a risk of developing subluxation, due to ligamentous laxity. Patients should refrain from playing any sport which causes high impact loading of the cervical spine, in particular, diving, weight lifting and rugby or football (16).

\section{Spondylolisthesis}

Patients with MFS have twice the incidence of spondylolisthesis compared to the general population (17). The slip angle is at least twice that of normal subjects, and may be further increased due to the presence of scoliosis. Symptomatic spondylolisthesis requires expert spinal fusion, which can be fraught with complications (17).

\section{Neonatal MFS}

Infantile scoliosis produces the most severe spinal deformities with significant cardio-pulmonary compromise. Advances in growing rod technology with magnet-driven growing rods (MdGRs) eliminate the need for repetitive anaesthesia, guiding curve correction with growth (18). Juvenile scoliosis in MFS is best treated by bracing for moderate curves, and then similar surgery for severe/ progressive curves. The advantage of this approach includes minimal absence from school, normal psychological maturation, improved scholastic performance, with one-off surgery and serial office-based lengthening.

\section{Pectus excavatum/carinatum}

Chest cage deformities may warrant surgery to increase the 
antero-posterior (AP) diameter of the chest and normalise the space available for the lungs by using a Nuss bar for pectus excavatum (19) for moderate pectus deformities, pressure bracing or suction, if applied during the growth period, may yield excellent results without resorting to surgery $(20,21)$. Surgery should be offered only if the chest deformity is causing respiratory or psychological problems. It should not usually be performed simply for cosmetic purposes. If a Nuss bar is required, in an adolescent who may well require open heart surgery at a later date, the pectus surgery should be delayed until after the open heart surgery, since removal of the Nuss bar at the time of heart surgery increases the surgery time.

\section{Rheumatological aspects}

Locomotor symptoms are frequent and troublesome in MFS $(15,22)$. Close involvement with rheumatologists and orthopedic surgeons may be indicated to manage painful joint hypermobility and complications in early to mid-life, and degenerative joint disease in later years. Seventy percent of children experience symptoms of arthralgia, back pain, and ligament laxity and injury (15). The earliest complaints are often knee pain or ankle pain necessitating rest and analgesia. It is important to allow the child to participate to the extent of his or her ability. Weak ankles and knees combine with poor eyesight may make the children appear clumsy in sporting activities, and this needs to be explained to the child's teachers. Shoes with ankle and arch supports often render the gait more controlled. Patellar dislocation can be a problem, and a full length tubigrip may be worn on the lower limb during sporting activities. In severe cases, surgical fusion of the ankle, or shortening of the patellar ligaments may be helpful. Joints gain stability with passing years. Wrist or finger splints may help to stabilise loose joints rendering writing neater. Extra time should be offered during written examinations. Use of a laptop computer for the older child avoids handwriting.

The Alexander method of correct posture, as well as stretching exercises, are helpful in managing joint pain. Chair and desk should be of adequate height for the tall child and adult.

Flat, long thin feet, often with hammer toes, require careful shoe fitting, with orthotics. Surgery for hammer toes can be helpful. Men with MFS are prone to spondylolisthesis and should avoid heavy lifting. Early osteoarthritis occurs in approximately $5 \%$ of families and the hip joint may need replacing by age 50. Protrusio acetabuli occurs with increased frequency (23).

Physiotherapists may be of great assistance, providing they understand that exercise alone will not markedly strengthen weak ligaments or muscles, but simply maintain optimum strength.

Medication, including non-steroidal anti-inflammatory medicines, should be prescribed on a regular basis, together with Omeprazole.

\section{Occupation and sports choice}

Moderate sporting activities on a regular basis, which are suited to the long lean frame, such as cycling, basketball, badminton, and swimming, are recommended. Sports which are not recommended involve possible damage to eyes, heart or skeleton (24). Occupation choice may be limited by physical ability and easy fatigability, and patients should be encouraged to prolong academic studies and enter a physically undemanding occupation of their interest. Early retirement due to easy fatigability may necessitate letters of support from the age of 50 onward to obtain early retirement on grounds of ill health (25). An early informed choice of less demanding occupations may prolong the working life of the patient.

\section{Pulmonary manifestations}

Pulmonary complications occur in up to $10 \%$ of patients $(26,27)$ and may present in infancy or childhood $(28)$. Complications may arise in adolescence or adult life that have serious consequences and are potentially fatal (29).

Fibrillin-1 deficiency can lead to flaccidity of small airways and bronchioles predisposing to premature airway closure, obstruction and air trapping. As a result, patients may have mildly abnormal lung function, usually manifesting as abnormalities in FEV1 and FVC (30). For those patients with kyphoscoliosis, a restrictive ventilatory effect is found, in keeping with the chest wall deformity. Pneumothorax, emphysema, subpleural apical blebs and restrictive or obstructive patterns of lung function are all reported (30).

\section{Pneumothorax}

An increased occurrence of pneumothorax especially in males has been reported with incidence up to $40 \%$ (31). Pneumothorax is more likely to recur, and studies have shown pulmonary bullae in patients especially in those who have had pneumothorax. Emphysema has 
been reported (32). The elastic fibres in lung biopsy specimens show degenerative changes, suggesting this as the likely explanation for lung function abnormalities. The management of pneumothorax with tube drainage, with or without pleurodesis is standard. However, it is recommended that early definitive surgical intervention is performed due to the increased incidence of recurrent disease (33). Smoking should be strongly discouraged.

Some patients at the severe end of the respiratory spectrum may require non-invasive ventilation in the perioperative period if having major cardiothoracic surgery.

\section{Bronchiectasis}

Case reports in both children (34) and adults $(27,29)$ are found in the literature. One reported survey of 100 adult patients found 2 cases of bronchiectasis, 3 with recurrent lower respiratory infections and 3 cases of tuberculosis (31). CT imaging is recommended, and one study found $13 \%$ of patients had bronchiectasis (35). Management of bronchiectasis in MFS is the same as for other patients with chronic bronchial sepsis.

\section{Interstitial lung disease}

Four cases of upper lobe fibrosis are reported amongst the 100 cases described by Wood et al. (31) and one report of bilateral honeycomb lung (36) exists.

\section{Obstructive sleep apnea (OSA)}

Kohler et al. (37) performed sleep studies in $61 \mathrm{MFS}$ patients and 26 matched control subjects. Results showed that more patients with MFS than controls had OSA (15.8\% compared with $11.5 \%)$. Mean aortic root diameter was significantly greater in patients with OSA compared to those without OSA. Sleep apnea should be assessed with sleep studies and treatment may include ENT surgery for enlarged adenoids or septal deviation, as well as intermittent nocturnal positive pressure ventilation (38).

\section{Anesthesia}

Intubating MFS patients may be difficult, due to high palate, reduced neck extension, and floppy central airways with narrow trachea. An experienced anesthetist should be present (6).

\section{Dental aspects}

Important characteristics include a long narrow face and skull, often with mandibular prognathism, and a high arched palate. The dentist may be the first one to suspect a diagnosis of MFS, and a child or adult with this feature should be referred for a genetic opinion and echocardiogram. In some cases, severe malocclusion and open bite may be associated, while weakened capsular ligaments and hyperextensibility of muscles can contribute to habitual subluxations or dislocations of the temporomandibular joint (TMJ) (39). Teeth tend to be crowded. Rarely, developmental abnormalities including supernumeraries, congenital absence, incomplete development, crown dysplasia, enamel hypoplasia, dentinogenesis imperfecta and multiple odontogenic cysts have been reported (40). The fibrillin defect may contribute to increased relapse after orthodontic treatment and increased periodontal problems (40).

\section{Dental management}

Some patients may need orthodontic and possibly oral surgical care. Careful planning from an early age can lead to successful cosmetic results (41). The prevention of bacterial endocarditis is all-important because of the high incidence of heart valve involvement, and an increased risk associated with previous cardiac surgery. Antibiotic prophylaxis should be considered for high-risk procedures in patients with prosthetic valves, including transcatheter valves or with repairs using prosthetic material and those with previous episodes of infective endocarditis (42). Recommendations regarding dental and cutaneous hygiene and strict aseptic measures during any invasive procedure are advised in this population. Antibiotic prophylaxis should be considered in dental procedures involving manipulation of the gingival or periapical region of the teeth or manipulation of the oral mucosa (42). National Institute of Clinical Excellence (NICE) guidelines for antibiotic prophylaxis are updated frequently (42), as are the European Society of Cardiology (ESC) guidelines (43).

Widening of the dental arch with internal bracing may make more room for teeth, reducing the necessity for dental extraction and bracing.

\section{ENT aspects}

Clinical findings in the ear, sinuses, nose and throat include a long narrow face with prominent supra-orbital ridges, large simple low set and posteriorly rotated ears, narrow ear canals which are angulated upward and forward. The nose is long, often beaked and asymmetrical, with narrow cavities and frequently deviated septum which may lead to complete 
blockage of one side of the nose (43). Mouth breathing may result. Sinuses may be narrow and underdeveloped with narrow drainage channels (44), therefore recurrent sinusitis is a common problem. Frequent spontaneous epistaxis may be a feature in childhood and adolescence, probably due to vascular wall fragility.

\section{Medical and surgical management}

Early recognition and prompt medical management of allergic rhinitis or sinusitis may prevent secondary infections. Antibiotics for infection should be used earlier and longer for longer than for an unaffected child or adult. Reduction in hearing due to recurrent otitis media is a common problem. Grommets may help resolve the problem of recurrent otitis media. However, early removal of tonsils and/or adenoids is recommended, as these structures are surprisingly large and can contribute to chronic otitis and sleep apnea (45). Surgical correction of deviated septum can be very helpful in management of mouth breathing and sleep apnea.

\section{Gastrointestinal symptoms}

In the sparse literature on this topic, reports are generally restricted to abnormal gastrointestinal anatomy. These include one report of diverticulosis coli (46), and one case of multiple problems including diaphragmatic hernia, inguinal hernia, diverticulosis coli, and Zenker's diverticulum (47). Both inguinal and diaphragmatic are known to be problems associated with MFS. Thakur et al. (48) reported a 25 -yearold female with acute abdominal pain for one day. CT revealed herniation through the lax dilated oesophageal hiatus, and at exploratory laparotomy, herniation of the stomach into the chest, part of ascending and transverse colon, splenic flexure and hernia omentum was revealed.

Recently, the first scientific study of gastrointestinal symptoms in MFS was reported (Scoones). In comparison with community controls, 118 MFS patients (56 men and 62 women) age (49) from 18-82 years, in a questionnaire survey, reported gastrointestinal disturbances, suffering more abdominal discomfort and irritable bowel syndrome (IBS). Forty per cent of the MFS group as compared to $15 \%$ of the control group reported symptoms of both types of IBS, namely diarrhea predominant or constipation predominant. This was not medication related. Abdominal discomfort was reported by 47 of the 118 MFS patients (40\%) but only $18 / 194$ (9\%) of the community controls $(\mathrm{P}<0.0001)$.

There is no blood test for IBS. However, more serious conditions such as celiac disease can be ruled out. Overactivity of the gut and intolerance to certain foods may play their part. Specific dietary advice and medical management should be sought through the general practitioner, who may refer to hospital dietician and gastroenterologist. Careful attention to diet, avoiding foods containing gluten such as wheat, dairy products, coffee and alcohol may be helpful, as well as eliminating stress and taking regular exercise (50-52).

To validate these results, further research with other populations of MFS patients should be performed.

\section{Neurosurgical problems}

While patients with MFS may frequently present to cardiothoracic surgeons, they are a rare entity in general neurosurgical practice and even more rarely require surgery. The range of symptoms and signs requiring referral to the relevant specialty, and appreciation of the increased surgical risks associated with treating MFS, are essential.

\section{Dural ectasia (DE)}

This condition is defined as enlargement of the neural canal anywhere along the spinal column, but nearly always in the lower lumbar and sacral regions, with thinning of the cortex of the pedicles and laminae of the vertebrae, widening of the neural foramina, or an anterior meningocele. DE has an incidence ranging from $63-92 \%$ of Ghent diagnostic criteria positive patients $(53,54)$. It is not specific to MFS and is prevalent in Ehlers-Danlos syndrome (55), a common overlapping condition. Abnormally weak connective tissues cause incompetence of the dural sac. In the majority of cases, DE is asymptomatic. However, DE may occur with moderate to severe back pain in patients (53\% of patients) in the largest series (14). Symptoms associated with anterior meningocele include abdominal discomfort, constipation and incontinence (56-59).

Headache is reported in $30 \%$ of MFS with DE. Patients reports an improvement when they are lying down, and worsening when they stand up.

\section{Diagnosis}

A number of methods have been put forward to best assess DE, namely conventional radiographs, CT, and MR imaging (55,60-62). A number of radiological features have been defined, including: anterior sacral meningocele; lateral herniation of the dura along the nerve root sleeves; dural sac 
ratios greater than 0.48 at $\mathrm{L} 5$ and greater than 0.57 at $\mathrm{S} 1$. This is the ratio between the dural sac diameter (DSD) measured on the midline sagittal image and the vertebral body diameter (VBD) at the same level (63). Further signs include scalloping of the vertebrae, and perineural or Tarlov cysts (cystic dilation containing spinal fluid along the nerve root) (64).

\section{Management}

Owing to the risk of cerebrospinal fluid (CSF) leak, plus the lack of long-term data on spinal stability, the majority of cases should be managed non-operatively. The combination of thin pedicles, thin laminae and weak connective tissue in MFS can make operative fixation of the Marfan spine perilous with a conservative estimate of dural tear rate of $8 \%$ and an $8 \%$ rate of adjacent segment laminar fracture (65). However, several reports present posterior laminectomy as a technique to relieve back pain secondary to DE (66-68).

Surgery for anterior sacral meningocele is not indicated for stable and asymptomatic lesions (69). The presence of escalating pelvic discomfort, neurologic deficit, altered bowel habit and urinary frequency may lead to surgery. The two classical approaches are either posteriorly via sacral laminectomy or anteriorly via an open transperitoneal approach. Management is complex and surgery should be reserved for selected cases requiring experienced allied general and neurological surgical input.

\section{Intracranial hypotension}

Spontaneous intracranial hypotension (SIH) is an important cause of new-onset headache, which is typically orthostatic in character and relieved by recumbency. It may be caused by a spinal CSF leak, due to a combination of weakness of the spinal meninges and a precipitating event. Subdural haematoma is a recognised complication, probably due to rupture of veins between the surface of the brain and the dura when the brain descends as CSF volume decreases. These changes appear on MRI scan as a 'sinking brain', with herniation of the cerebellar tonsils through the foramen magnum.

Conservative management may include bed rest, hydration, analgesia, high-salt diet and caffeine in the first instance (70). Refractory cases may require epidural venous blood patching (71) and a period of flat bed rest. In most cases, the suspected site of CFS leak is lumbosacral ectatic dura.

\section{Migraine}

A questionnaire study of 457 MFS patients (72) and a multi-centre study of 123 MFS patients (73) found that the lifetime prevalence of migraine with aura is increased in patients with MFS. There is an increased incidence of migraine in connective tissue disorders including EhlersDanlos syndrome which may be due to matrix degeneration observed in the systemic blood vessels resulting in an endothelial cell reaction (72-74).

\section{Genitourinary tract in women}

Pelvic organ prolapse and urinary stress incontinence in women are increased in MFS, probably due to decreased strength and resilience of the connective tissue of the pelvis. Stress incontinence is associated with hypermobility of the bladder neck as well as intrinsic sphincter weakness. Hypermobility of the bladder neck can be elicited on physical examination with the presence of cystourethrocele. Ehlers-Danlos syndrome, a connective tissue disorder involving collagen, is associated with incontinence $(74,75)$.

A postal survey was undertaken with 240 questionnaires sent to men and women to elicit the presence of diseases involving renal, urinary and reproductive systems, receiving responses from 42 females with a mean age of 41 years (range, 14-63 years) (76).

There were 14 positive responses to the question regarding stress incontinence, corresponding to a $33 \%$ crude prevalence rate of stress incontinence in this group.

An observational study by Jabs involved recruitment of 75 adult female subjects from the MFS clinic of Dr. Anne Child. Only 59 patients were contactable, and of the 25 who agreed to participate, 14 underwent interview, questionnaire and examination while an additional 11 were interviewed by telephone and completed the postal questionnaire. A standard urinary symptom questionnaire was used (77). Physical examination included joint hypermobility using the Beighton joint score (78). Pelvic examination was carried out with prolapse staging recorded according to the International Continence Society Guidelines, in the left lateral position at maximum Valsalva manoeuvre. Joint hypermobility was found not to be correlated with pelvic organ prolapse or stress incontinence.

A history of urinary incontinence was elicited in 22/25 $(88 \%)$ of patients, of whom $13 / 25$ (52\%) considered the problems significant. Five had undergone surgical treatment for stress incontinence. Parity was not associated with stress incontinence in this population.

Nine women had stage II prolapse on examination, one patient had undergone Manchester repair. Overall, 
$11 / 25$ (44\%) of the total group had history or evidence of prolapse. Six women (24\%) had undergone surgical treatment for prolapse.

An abstract by Carley and Schaffer at the American Urogynecologic Society Meeting 1998, presented interview data on 12 women with MFS and found a rate of urinary incontinence of $42 \%$ and pelvic organ prolapse of $33 \%$ (79).

The prevalence of incontinence and pelvic organ prolapse in the general population is not easily ascertained (80) however; a prevalence of approximately $30 \%$ for incontinence is a clinically useful figure. In a study by Jabs (76), $88 \%$ of women with MFS had experienced urinary incontinence and $72 \%$ had experienced episodes of stress incontinence. These rates are considerably higher than those quoted for the general population.

The prevalence of pelvic organ prolapse in the general population in women 20-59 years of age found a prevalence of $30.8 \%$ for any degree of prolapse (81). In Jabs' study, of the 14 women examined, 9 (64\%) had stage II pelvic organ prolapse of whom 5 were recurrent and 3 occurred in nulliparous women.

\section{Management}

A trial of conservative therapy for prolapse, such as vaginal pessary, should be considered. Anterior repair is less effective treatment for stress incontinence in the general population $(82,83)$ and should also be avoided in this population with high risk of recurrence. A colposuspension using the strong attachment point of the iliopectineal ligament and permanent suture or a vaginal tape may prove more successful for treatment of stress incontinence.

These patients should be counselled to minimize additional risk factors such as constipation, straining at stool, chronic cough, heavy lifting and increased body weight. Pelvic floor exercises should be encouraged.

Patients with MFS have delayed wound healing due to abnormal fibrillin production, and their vasculature is fragile, which can lead to increased blood loss (84). They should be considered at higher risk for incisional hernia and dehiscence. Meticulous surgical technique is required with attention to hemostasis and the use of suture material with prolonged delayed absorption, or non-absorbable suture where possible. Suture and staple removal should be delayed compared with patients who have normal wound healing. Antibiotic prophylaxis is required to prevent bacterial endocarditis.

Effective treatment for cardiovascular complications has increased the life expectancy for these patients (85). As a result, patients will more commonly experience diseases which increase in prevalence with age, such as incontinence and pelvic organ prolapse. Input from a gynecologist or urogynecologist should be sought when appropriate.

\section{Acknowledgements}

The author is grateful for the support of the British Heart Foundation, Marfan Trust, Marfan Association UK, Bluff Field Charitable Trust, Rosetrees Trust, St George's University of London, St George's University Hospitals NHS Foundation Trust, and all participating Marfan syndrome patients.

\section{Footnote}

Conflicts of Interest: The author has no conflicts of interest to declare.

\section{References}

1. Hall JR, Pyeritz RE, Dudgeon DL, et al. Pneumothorax in the Marfan Syndrome; prevalence and therapy. Ann Thorac Surg 1984;37:500-4.

2. National Marfan Foundation. Available online: www. marfan.org/resources/professionals/management

3. Erbel R, Aboyans V, Boileau C, et al. 2014 ESC Guidelines on the diagnosis and treatment of aortic diseases: Document covering acute and chronic aortic diseases of the thoracic and abdominal aorta of the adult. The Task Force for the Diagnosis and Treatment of Aortic Diseases of the European Society of Cardiology (ESC). Eur Heart J 2014:35:2873-926

4. Verghese C. Anaesthesia in Marfan Syndrome. Anaesthesia 1984;39:917-22.

5. Faivre L, Collod-Beroud G, Loeys BL, et al. Effect of mutation type and location on clinical outcome in 1,013 probands with Marfan syndrome or related phenotypes and FBN1 mutations: an international study. Am J Hum Genet 2007;81:454-66.

6. Faivre L, Masurel-Paulet A, Collod-Beroud G, et al. Clinical and molecular study of 320 children with Marfan syndrome and related type I fibrillinopathies in a series of 1009 probands with pathogenic FBN1 mutations. Pediatrics 2009;123:391-8.

7. Arslan-Kirchner M, Arbustini E, Boileau C, et al. Clinical utility gene card for: Marfan syndrome type 1 and related phenotypes [FBN1]. Eur J Hum Genet 2010;18. 
8. Chandra A, Ekwalla V, Child A, et al. Prevalence of ectopia lentis and retinal detachment in Marfan syndrome. Acta Ophthalmol 2014;92:e82-3.

9. Chandra A, Charteris D. Molecular pathogenesis and management strategies of ectopia lentis. Eye (Lond) 2014;28:162-8.

10. Hubbard AD, Charteris DG, Cooling RJ. Vitreolensectomy in Marfan's syndrome. Eye (Lond) 1998;12:412-6.

11. Wagoner MD, Cox TA, Ariyasu RG, et al. Intraocular lens implantation in the absence of capsular support: a report by the American Academy of Ophthalmology. Ophthalmology 2003;110:840-59.

12. Izquierdo NJ, Traboulsi EI, Enger C, et al. Strabismus in the Marfan syndrome. Am J Ophthalmol 1994;117:632-5.

13. Heur M, Costin B, Crowe $S$, et al. The value of keratometry and central corneal thickness measurements in the clinical diagnosis of Marfan syndrome. Am J Ophthalmol 2008;145:997-1001.

14. Sponseller PD, Hobbs W, Riley LH 3rd, et al. The thoracolumbar spine in Marfan syndrome. J Bone Joint Surg Am 1995;77:867-76.

15. Grahame R, Pyeritz RE. The Marfan syndrome: Joint and skin manifestations are prevalent and correlated. Br J Rheumatol 1995;34:126-31.

16. Hobbs WR, Sponseller PD, Weiss AP, et al. The cervical spine in Marfan syndrome. Spine 1997;22:983-9.

17. Sponseller PD. Chapter 103 - Spinal deformities in Marfan Syndrome. In: Bridwell KH, De Wald R, editors. The textbook of spinal surgery, 3rd edition. Lippincott Williams \& Wilkins, 2012.

18. Harshavardhana NS, Noordeen MH. Spinal Deformity in Marfan Syndrome (MFS). In: Child A. editor. Diagnosis and Management of Marfan Syndrome. London: Springer, 2016:145-64.

19. Sugrue PA, O'Shaughnessy BA, Blanke KM, et al. Rapidly progressive Scheuermann's disease in an adolescent after pectus bar placement treated with posterior vertebralcolumn resection: case report and review of the literature. Spine 2013:38:E259-62.

20. Lopez M, Patoir A, Costes F, et al. Preliminary Study of Efficacy of cup suction in the correction of typical pectus excavatum. J Pediatr Surg 2016;51:183-7.

21. Emil S, Sévigny M, Montpetit K, et al. Success and duration of dynamic bracing for pectus carinatum: A fouryear prospective study. J Pediatr Surg 2017;52:124-9.

22. Magrid D, Pyeritz RE, Fisherman EK. Musculo-skeletal manifestation of the Marfan syndrome. Am J Rheumatol
1992;155:99-104.

23. Kuhlman JE, Scott WW Jr, Fishman EK, et al. Acetabular protrusion in the Marfan Syndrome. Radiology 1987;164:415-7.

24. Davies B, Child AH. Exercise in Marfan syndrome. In: Child AH. editor. Diagnosis and Management of Marfan Syndrome. London UK: Springer Verlag, 2016:263-72.

25. Hasan A, Poloniecki J, Child AH. Ageing in Marfan syndrome. Int J Clin Pract 2007;61:1308-20.

26. McKusick V. Heritable disorders of connective tissue. 4th edition. Oxford: CV Mosby, Blackwell Scientific Publications, 1972.

27. Foster ME, Foster DR. Bronchiectasis and Marfan's Syndrome. Postgrad Med J 1980;56:718-9.

28. Dominguez R, Weisgrau RA, Santamaria M. Pulmonary hyperinflation and emphysema in infants with the Marfan syndrome. Pediatr Radiol 1987;17:365-9.

29. Saito H, Iijima K, Dambara T, et al. An autopsy case of Marfan Syndrome with bronchiectasis and multiple bullae. Nihon Kyobu Shikkan Gakkai Zasshi 1992;30:1315-21.

30. Streeten EA, Murphy EA, Pyeritz RE. Pulmonary function in the Marfan Syndrome. Chest 1987;91:408-12.

31. Wood JR, Bellamy D, Child AH, et al. Pulmonary disease in patients with Marfan syndrome. Thorax 1984;39:780-4.

32. Turner JA, Stanley NN. Fragile lung in Marfan syndrome. Thorax 1976;31:771-75.

33. Dwyer EM, Troncale F. Spontaneous pneumothorax and pulmonary disease in the Marfan Syndrome. Ann Intern Med 1965;62:1285-92.

34. Teoh PC. Bronchiectasis and spontaneous pneumothorax in Marfan Syndrome. Chest 1977;72:672-73.

35. Hwang HS, Yi CA, Yoo H, et al. The prevalence of bronchiectasis in patients with Marfan syndrome. Int J Tuberc Lung Dis 2014;18:995-7.

36. Lipton RA, GreenwaId A, Seriff NS. Pneumothorax and bilateral honeycombed lung in Marfan Syndrome. Am Rev Respir Dis 1971;104:924-8.

37. Kohler M, Blair E, Risby P, et al. The prevalence of obstructive sleep apnoea and its association with aortic dilatation in Marfan's syndrome. Thorax 2009;64:162-6.

38. Kohler M, Pitcher A, Blair E, et al. The impact of obstructive sleep apnea on aortic disease in Marfan's syndrome. Respiration 2013;86:39-44.

39. Crosher R, Holmes A. Marfan Syndrome: Dental problems and management. Dent Update 1988;15:120-2.

40. Scott DC. Frontier Dentistry Part 3 - Marfan Syndrome An oral perspective. Ont Dent 1982;59:54-9.

41. Gazit E, Lieberman NI. Severe maxillary constriction in a 
patient with Marfan Syndrome: report of a case. ASDC J

Dent Child 1981;48:292-3.

42. NICE Clinical Guideline 64. Prophylaxis against infective endocarditis. Issue date: March 2008. Section 2.5.1.

43. Habib G, Lancelotti P, Antunes MJ, et al. ESC guidelines for the management of infective endocarditis: the Task Force for the Management of Infective Endocarditis of the European Society of Cardiology (ESC). Eur Heart J 2015;36:3075-128.

44. Cistulli PA, Sullivan CE. Influence of maxillary morphology on nasal airway resistance in Marfan's syndrome. Acta Otolaryngol 2000;120:410-3.

45. Rybczynski M, Koschyk D, Karmeier A, et al. Frequency of sleep apnea in adults with the Marfan syndrome. Am J Cardiol 2010;105:1836-41

46. Suster SM, Ronnen M, Bubis JJ. Diverticulosis coli in association with Marfan syndrome. Arch Intern Med 1984;144:203.

47. Eliashar R, Sichel JY, Biron A, et al. Multiple gastrointestinal complications in Marfan syndrome. Postgrad Med J 1998;74:495-7.

48. Thakur S, Jhobta A, Sharma B, et al. Unusual presentation of adult Marfan syndrome as a complex diaphragmatic hiatus hernia. Asian J Surg 2017;40:313-6.

49. Scoones B, Child AH. Gastrointestinal symptoms in patients with Marfan syndrome. In: Child AH. editor. Diagnosis and Management of Marfan syndrome. London, UK: Springer Verlag, 2016:189-200.

50. Irritable Bowel Syndrome, NICE Clinical Guidelines CG61 (2008) (Updated 2015). Irritable bowel syndrome in adults: diagnosis and management. Available online: www. nice.org.uk/guidance/cg61

51. Jones R. Treatment of irritable bowel syndrome in primary care. BMJ 2008;337:a2213.

52. IBS Treatment Options, International Foundation for Functional Gastrointestinal Disorders (IFFGD). Sept 2014. Available online: www.aboutibs.org

53. Pyeritz RE, Fishman EK, Bernhardt BA, et al. Dural ectasia is a common feature of the Marfan syndrome. Am J Hum Genet 1988;43:726-32.

54. Mesfin A, Ahn NU, Carrino JA, et al. Ten-year clinical and imaging follow-up of dural ectasia in adults with Marfan syndrome. Spine J 2013;13:62-7.

55. Villeirs GM, Van Tongerloo AJ, Verstraete KL, et al. Widening of the spinal canal and dural ectasia in Marfan's syndrome: assessment by CT. Neuroradiology 1999;41:850-4.

56. Ahn NU, Sponseller PD, Ahn UM, et al. Dural ectasia is associated with back pain in Marfan syndrome. Spine (Phila Pa 1976) 2000;25:1562-8.

57. Stern WE. Dural ectasia and the Marfan syndrome. J Neurosurg 1988;69:221-7.

58. Raftopoulos C, Pierard GE, Rétif C, et al. Endoscopic cure of a giant sacral meningocele associated with Marfan's syndrome: case report. Neurosurgery 1992;30:765-8.

59. Strand RD, Eisenberg HM. Anterior sacral meningocele in association with Marfan's syndrome. Radiology 1971;99:653-4.

60. Ahn NU, Sponseller PD, Ahn UM, et al. Dural ectasia in the Marfan syndrome: MR and CT findings and criteria. Genet Med 2000;2:173-9.

61. Ahn NU, Nallamshetty L, Ahn UM, et al. Dural ectasia and conventional radiography in the Marfan lumbosacral spine. Skeletal Radiol 2001;30:338-45.

62. Oosterhof T, Groenink M, Hulsmans FJ, et al. Quantitative assessment of dural ectasia as a marker for Marfan syndrome. Radiology 2001;220:514-8.

63. Acosta FL Jr, Quinones-Hinojosa A, Schmidt MH, et al. Diagnosis and management of sacral Tarlov cysts. Case report and review of the literature. Neurosurg Focus 2003;15:E15.

64. Jones KB, Erkula G, Sponseller PD, et al. Spine deformity correction in Marfan syndrome. Spine (Phila Pa 1976) 2002;27:2003-12.

65. Smith MD. Large sacral dural defect in Marfan syndrome. A case report. J Bone Joint Surg Am 1993;75:1067-70.

66. Weir B. Leptomeningeal cysts in congenital ectopia lentis. Case report. J Neurosurg 1973;38:650-4.

67. Cilluffo JM, Gomez MR, Reese DF, et al. Idiopathic ("congenital") spinal arachnoid diverticula. Clinical diagnosis and surgical results. Mayo Clin Proc 1981;56:93-101.

68. Anderson FM, Burke BL. Anterior sacral meningocele. A presentation of three cases. JAMA 1977;237:39-42.

69. Rosser T, Finkel J, Vezina G, et al. Postural headache in a child with Marfan syndrome: case report and review of the literature. J Child Neurol 2005;20:153-5.

70. Albayram S, Baş A, Ozer H, et al. Spontaneous intracranial hypotension syndrome in a patient with marfan syndrome and autosomal dominant polycystic kidney disease.

Headache 2008;48:632-6.

71. Vis JC, Timmermans J, Post MC, et al. Increased prevalence of migraine in Marfan syndrome. Int J Cardiol 2009;136:330-4.

72. Koppen H, Vis JC, Gooiker DJ, et al. Aortic root pathology in Marfan syndrome increases the risk of migraine with aura. Cephalalgia 2012;32:467-72. 
73. Knudsen S, Russell MB. Increased risk of migraine in Marfan's syndrome? Acta Neurol Scand 2006;114:281-6.

74. McIntosh LJ, Mallett VT, Frahm JK, et al. Gynecologic disorders in women with Ehlers-Danlos syndrome. J Soc Gynecol Investig 1995;2:559-64.

75. McIntosh LJ, Stanitski DF, Mallett VT, et al. EhlersDanlos syndrome: relationship between joint hypermobility, urinary incontinence and pelvic floor prolapse. Gynecol Obstet Invest 1996;41:135-9.

76. Jabs C, Child AH. Genitourinary Tract in Women with Marfan Syndrome. In: Child AH. editor. Diagnosis and Management of Marfan Syndrome. London UK: SpringerVerlag, 2016:219-25.

77. Jackson S, Donavan J, Brookes S, et al. The Bristol female lower urinary tract symptoms questionnaire: development and psychometric testing. Br J Urol 1996;77:805-12.

78. Beighton P, Solomon L, Soskolne CL. Articular mobility in an African population. Ann Rheum Dis 1973;32:413-8.

79. Schaffer JI. Urogynaecological Problems in Women with Marfan Syndrome (Abstract). Proceedings of American

Cite this article as: Child AH. Non-cardiac manifestations of Marfan syndrome. Ann Cardiothorac Surg 2017;6(6):599-609. doi: 10.21037/acs.2017.10.02
Urogynecologic Society Meeting, 1998.

80. Hampel C, Wienhold D, Denker N, et al. Definition of overactive bladder and epidemiology of urinary incontinence. Urology 1997;50:4-14.

81. Samuelsson EC, Victor FT, Tibblin G, et al. Signs of genital prolapse in a Swedish population of women 20 to 59 years of age and possible related factors. Am J Obstet Gynecol 1999;180:299-305.

82. Black NA, Downs SH. The effectiveness of surgery for stress incontinence in women: a systematic review. Br J Urol 1996;78:497-510.

83. Leach GE, Dmochowski RR, Appell RA, et al. Female stress urinary incontinence clinical guidelines panel summary report on surgical management of female stress urinary incontinence. J Urol 1997;158:875-80.

84. Bridges AB, Fisher TC, McLaren M, et al. Endothelial Cell and Platelet Function in Marfan's Syndrome. Endothelium 1993;1:203-6.

85. Silverman DI, Burton KJ, Gray J, et al. Life expectancy in the Marfan syndrome. Am J Cardiol 1995;75:157-60. 